\title{
Phytohormone content variation manipulated by Bemisia tabaci participated in inhibiting tobacco growth: Gibberellin may play a crucial role
}

\author{
Xia Sun ${ }^{1}$, Haipeng Zhao ${ }^{1}$, Yanan $\mathrm{Xu}^{1}$, Xiao Zhang ${ }^{2}$, Xin Liang ${ }^{1}$, and Ming Xue ${ }^{1 *}$ \\ ${ }^{1}$ Shandong Agricultural University, College of Plant Protection, Tai' an 271018, Shandong, China. \\ "Corresponding author (xueming@sdau.edu.cn). \\ ${ }^{2}$ Ji'nan Center for Disease Control and Prevention, Ji’nan 250021, Shandong, China.
}

Received: 7 September 2019; Accepted: 16 December 2019; doi:10.4067/S0718-58392020000100090

\begin{abstract}
Infestation of Bemisia tabaci MEAM1 (Gennadius) causes significant phenotypic changes in a variety of plants. However, plants damaged by Trialeurodes vaporariorum (Westwood) show no similar changes. In this study, to explore the effects of MEAM1 infestation on tobacco growth and the mechanism underlying these effects, growth index, and photosynthesis of infested tobacco (Nicotiana tabacum L.), as well as content of hormones, including auxin, gibberellin, cytokinin, abscisic acid, methyl jasmonate, and ethylene were measured. The results demonstrated that infestation of MEAM1 significantly inhibited tobacco growth and the inhibition effect varied with MEAM1 feeding densities, 50 MEAM1 per infested tobacco plant decreased plant height, internode length, and dry weight $\mathrm{cm}^{-2}$, and this inhibition peaked at 200 MEAM1 per plant, which reduced by $52.17 \%, 43.83 \%$, and $45.61 \%$ that of controls, respectively. Additionally, MEAM1 infestation inhibited photosynthesis of tobacco, causing significant decrease in chlorophyll content, photosynthetic rate and stomatal conductance. However, the effects of T. vaporariorum infestation on tobacco were significantly lighter than that of MEAM1. Hormones assays indicated that infestation with 200 MEAM1 per plant for $30 \mathrm{~d}$ significantly affected hormones content, among which gibberellin content was specifically reduced compared with that of uninfested control plants and T. vaporariorum infested plants. Furthermore, exogenous application of 1 and $2 \mu \mathrm{M}$ gibberellin alleviated the reduction in plant height mediated by MEAM1. Therefore, infestation of MEAM1 significantly inhibited tobacco growth and photosynthesis, and the reduction of gibberellin content may contribute to this inhibition.
\end{abstract}

Key words: Bemisia tabaci MEAM1, growth inhibition, photosynthesis, phytohormones.

\section{INTRODUCTION}

In nature, plants suffer from various abiotic and biotic stresses. These stresses can affect all life processes of plants, change plant morphology, inhibit plant growth, and reduce crop yields (Alonso-Ramirez et al., 2009; Su et al., 2017). Herbivory is one of the crucial stresses affecting plants growth (De Bruyne et al., 2014). The effects of phloem-feeding insect infestation on host plants are more complicated, despite they only cause minor wounds (Stephens and Westoby, 2015). These phloem-feeding insects may inhibit plant growth and reduce crop yields via consuming plant nutrients, reducing plant photosynthesis, and/or manipulating plant hormone interaction (Su et al., 2017).

Photosynthesis is an important physiological indicator of plant growth, and its intensity determines the production level of crops ( $\mathrm{Li}$ et al., 2013; 2018). Studies have proved that herbivores feeding can impair the function of chloroplasts and stoma thereby affect photosynthesis (Cheng et al., 2018). For instance, when Tetranychus urticae feed on soybean (Glycine max L.), significant photosynthetic rate reduction is observed due to stomatal limitation (Bueno et al., 2009). 
Aphid (Brevicoryne brassicae L.) feeding causes obviously decrease in chlorophyll index, photosynthetic rate and stomatal conductance of Brassica carinata, thus resulting in a significant reduction in crop growth and yield (Pandey et al., 2013; Su et al., 2017).

Plant hormones are crucial factors closely related to plant growth. Most stages of plant growth and development are affected by various hormones, including the major growth regulators, auxin, cytokinin (CK), and gibberellin (GA), and the defensive hormones, abscisic acid (ABA), jasmonic acid (JA), ethylene (ETH), and salicylic acid (SA) (Wolters and Jurgens 2009; De Bruyne et al., 2014). Recent studies indicate that pathogens and herbivores can impact plant growth through manipulating plant hormone signaling pathways (Zhang et al., 2015; 2017b). For instance, Fiorinia externa (Ferris) (Hemiptera: Diaspididae) infestation significantly increase JA and ABA content of East Asian hemlocks, causing severe yield loss (Schaeffer et al., 2018). Chilo suppressalis (Walker) (Lepidoptera: Pyralidae) feeding can enhance JA content while suppressing the accumulation of GA, thus leading to a dwarf phenotype and increased resistance in affected rice plants ( $\mathrm{Li}$ et al., 2015). Among these plant hormones, GAs is a series of tetracyclic diterpenoid hormones, which play important roles in many processes of plant growth and development, including cell expansion, seed germination, floral development, chlorophyll degradation and accumulation (Li et al., 2010). Recent researches have proved that GA is also involved in plant responses to abiotic and biotic stresses (Pusittigul et al., 2012; Kim et al., 2016). Cold and salt stresses usually inhibit GA signal in host plants, resulting in a reduction in seed germination rate and dwarfism (Alonso-Ramirez et al., 2009; Zhu et al., 2016). However, studies focus on the impact of herbivore attacks on growth-related hormones in hosts is rarely.

Bemisia tabaci (Gennadius) (Hemiptera: Aleyrodidae) MEAM1 (Middle East-Asia Minor 1) and Trialeurodes vaporariorum (Westwood) (Hemiptera: Aleyrodidae) are common sap-sucking pests, and important global agricultural pests (Zhang et al., 2015). As a worldwide invasion pest, MEAM1 causes serious agricultural losses (Ballina-Gomez et al., 2013; Costa et al., 2017). MEAM1 infestation causes various phenotypic changes, for instance, silverleaf whitefly infested squash (Cucurbita pepo L.) plants displays silverleaf symptoms (Masuda et al., 2016; Zhang et al., 2017a). Furthermore, MEAM1 infestation in tobacco and Arabidopsis induces defense response to the subsequent insects via activating SA signaling pathways (Xue et al., 2010; Zhang et al., 2013). However, it is not clear if T. vaporariorum feeding shows similar phenomenon.

In this study, a whitefly-plant model was built by treating MEAM1 as the target insect and $T$. vaporariorum as the control insect. The plant growth inhibition effects, changes of photosynthetic indices and plant hormones contents mediated by MEAM1 and $T$. vaporariorum were compared using photosynthesis measurer, enzyme linked immunosorbent and exogenous spraying technique. The objective of this investigation was to answer the following questions: 1 . Whether MEAM1 and T.vaporariorum infestation cause similar effect on growth and photosynthesis of tobacco plants. 2 . Whether hormone contents variation is different after infestation of MEAM1 and T. vaporariorum. 3 . Whether hormone is closely related to the inhibition effect. This study focused on the disparities between MEAM1 and T. vaporariorum on plant growth, which may help to elucidate possible underlying mechanisms of MEAM1 mediated host growth inhibition.

\section{MATERIALS AND METHODS}

\section{Plant and insect materials}

Tobacco (Nicotiana tabacum L.) 'Xanthi-nc' seeds used for the experiment were supplied by Tobacco Breeding Laboratory, Shandong Agricultural University, Tai' an, Shandong Province, China. Seeds were planted in nursery trays $(50 \mathrm{~cm} \times 25 \mathrm{~cm})$ filled with perlite and vermiculite $(2: 1)$. At two-leaf development stage, seedlings were individually transplanted into pots $(10 \mathrm{~cm} \times 12 \mathrm{~cm})$ containing nursery substrate. Plant was fertilized by fertilizer $\left(100 \mathrm{~g} \mathrm{~N} \mathrm{~L}^{-1}, 40 \mathrm{~g}\right.$ $\mathrm{P}_{2} \mathrm{O}_{5} \mathrm{~L}^{-1}, 70 \mathrm{~g} \mathrm{~K}_{2} \mathrm{O} \mathrm{L}{ }^{-1}+$ trace elements). Plants at the five-leaf development stage were used for experiments.

Bemisia tabaci MEAM1 (Middle East-Asia Minor 1) strain was originally collected from cabbage plants, and identified based on the mitochondrial cytochrome oxidase I gene sequence. Trialeurodes vaporariorum strain was originally collected from tobacco plants. Prior to use in the study, the insects were maintained separately on tobacco in growth chambers $\left(23 \pm 2{ }^{\circ} \mathrm{C}, 75 \pm 5 \% \mathrm{RH}, 10: 14 \mathrm{~h}\right.$ photoperiod) for more than 30 generations.

All bioassay experiments were carried out in a growth chamber $\left(23 \pm 2{ }^{\circ} \mathrm{C}, 75 \pm 5 \% \mathrm{RH}, 10: 14 \mathrm{~h}\right.$ photoperiod $)$. 


\section{Whitefly pre-infestation}

The whitefly pre-infection method was slightly modified with reference to Xue et al. (2010). Twelve five-leaf-stage tobacco plants were placed in a separate gauze-covered cage $(60 \mathrm{~cm} \times 60 \mathrm{~cm} \times 60 \mathrm{~cm}, 80 \mathrm{mesh})$ with about $50( \pm 5), 100$ $( \pm 10), 200( \pm 10)$ whitefly adults $(1: 1=$ female:male, approximately) per plant, respectively. Tobacco plants without whitefly were placed in insect-proof screened cages as controls. All infection experiments were carried out in growth chambers $\left(23 \pm 2{ }^{\circ} \mathrm{C}, 75 \pm 5 \% \mathrm{RH}, 10: 14 \mathrm{~h}\right.$ photoperiod $)$.

\section{Determination of growth indexes}

The measurement method of growth indexes is slightly modified with reference to Li et al. (2013).

After being infested with whitefly for 0,10,20 and $30 \mathrm{~d}$, plant height, internode length was measured, and number of leaves was recorded. There were 12 replicates for each experiment.

After feeding of whitefly for $30 \mathrm{~d}$, third-leaf (lower leaf), fifth-leaf (middle leaf), and seventh-leaf (upper leaf) were taken for measurements. Leaf area was measured using portable laser leaf area meter (AM350, ADC BioScientific, Hoddesdon, UK). Using a punch (1 $\mathrm{cm}$ in diameter) leaf discs were taken from the seventh-leaf (upper leaf) and then dried in oven at $80{ }^{\circ} \mathrm{C}$ for $24 \mathrm{~h}$. Dry weight was recorded and dry weight $\mathrm{cm}^{-2}$ was calculated. There were 12 replicates for each experiment.

\section{Determination of photosynthetic indexes}

After feeding of whitefly for $30 \mathrm{~d}$, seventh-leaf (upper leaf) was chosen for measurement. According to the methods of Li et al. (2013), chlorophyll ( $a$ and $b$ ) content of leaves from infested and uninfested plants were measured using a spectrophotometer (Thermo Spectronic, Cambridge, UK). There were four replicates for each experiment.

After feeding of whitefly for $30 \mathrm{~d}$, photosynthetic indexes were measured on seventh-leaf (upper leaf) from infested and uninfested tobacco plants using a portable photosynthesis system (Ciras-3, PP Systems, Amesbury, Massachusetts, USA). The measured photosynthesis indexes included: photosynthetic rate, transpiration rate, stomatal conductance, and internal $\mathrm{CO}_{2}$ concentration. The experiments were carried out in growth chamber $\left(25^{\circ} \mathrm{C}, 80 \% \mathrm{RH}, 350 \mu \mathrm{mol} \mathrm{mol}^{-1} \mathrm{CO}_{2}\right.$ concentration, $800 \mu \mathrm{mol} \mathrm{m}^{-2} \mathrm{~s}^{-1}$ light intensity) from 10:00 to 11:00 h. There were 12 replicates for each experiment.

\section{Quantification of phytohormones}

After MEAM1 infested $30 \mathrm{~d}$, seventh-leaf (upper leaf) were sampled.

Ethylene content was determined using gas chromatography with a flame ionization detector (FID) and column $4 \times$ 2000 mm, GDX 502 (Shimadzu Corp., Kyoto, Japan). Fresh leaves $(0.5 \mathrm{~g})$ collected from each replicate were put into a tube containing $5 \mathrm{~mL}$ mixture of mercuric chloride and perchloric acid, the material was completely immersed in the reaction solution. After $20 \mathrm{~h}$, it was transferred to a mortar for grinding, the homogenate was centrifuged for $10 \mathrm{~min}$ at $5000 \mathrm{~g}$ at $4{ }^{\circ} \mathrm{C} ; 1 \mathrm{~mL}$ supernatant was taken in a Waters sample vial (Waters Corporation, Milford, Massachusetts, USA). To this, $1 \mathrm{~mL}$ of $2 \mathrm{~mL} \mathrm{~L}^{-1} \mathrm{HCl}$ was added, cap quickly tightened, and the mixture was vibrated on a mixer for $5 \mathrm{~s}$, and then placed in a $30^{\circ} \mathrm{C}$ water bath for $5 \mathrm{~h}$. Then, $1 \mathrm{~mL}$ saturated sodium chloride solution was injected into the vial through the rubber cap with a syringe, and $1 \mathrm{~mL}$ gas sample was taken with another syringe to determine the ethylene content by gas chromatography. There were four replicates for each experiment.

Auxin, gibberellin, cytokinin, abscisic acid, and methyl jasmonate contents were determined using enzyme linked immunosorbent assay (ELISA). The antibodies for the ELISA test were supplied by the Institute of Plant Hormone (China Agricultural University, Beijing, China). In brief, $0.2 \mathrm{~g}$ fresh tobacco leaves were extracted for $24 \mathrm{~h}$ at $4{ }^{\circ} \mathrm{C}$, and then purified by $\mathrm{C}_{18}$ Sep-Pak cartridges (Waters Corporation). Microtiter plates were coated with $50 \mu \mathrm{L}$ samples and hormone antigen $(0.25 \mu \mathrm{g} \mathrm{mL}-1)$. Then the coated plate was incubated at $37^{\circ} \mathrm{C}$ for $45 \mathrm{~min}$. Next, each well was added with $100 \mu \mathrm{L}$ antibody $(20 \mu \mathrm{g} \mathrm{mL}-1)$ and incubated for another $1 \mathrm{~h}$ at $37^{\circ} \mathrm{C}$. Finally, $100 \mu \mathrm{L}$ color-developing solution containing $2 \mathrm{mg} \mathrm{mL}^{-1} o$-phenylenediamine and $0.008 \%(\mathrm{v} / \mathrm{v}) \mathrm{H}_{2} \mathrm{O}_{2}$ was added to each well, and the plate was incubated at $37{ }^{\circ} \mathrm{C}$ for $15 \mathrm{~min}$ in the darkness, subsequently terminated using $50 \mu \mathrm{L} 2 \mathrm{M} \mathrm{H}_{2} \mathrm{SO}_{4}$ per well. The absorbance was recorded at $490 \mathrm{~nm}$. There were four replicates for each experiment. 


\section{Chemical treatment and plant growth determination}

After being infested with whitefly for 5, 15, and $25 \mathrm{~d}$, the infested tobacco plants were sprayed with deionized water and $0.5,1.0$ and $2.0 \mu \mathrm{M}$ gibberellin, respectively. Tobacco plants without whitefly were sprayed with the same liquids as controls. The height of infested and uninfested tobacco was measured in each treatment after $30 \mathrm{~d}$ of MEAM1 infection. There were 12 replicates for each experiment.

\section{Statistical analyses}

Data were statistically analyzed using the software package SPSS 18.0 for Windows (IBM, Armonk, New York, USA). An ANOVA was performed to analyzing the data, and then Tukey's multiple comparison tests was used to compare the differences among treatments with a significance level of $5 \%(P \leq 0.05)$.

\section{RESULTS}

Effects of MEAM1 and T. vaporariorum infestation on tobacco plant growth

Compared to the control and T. vaporariorum infested plants, MEAM1 infestation significantly inhibited tobacco growth. As low as $50( \pm 5)$ MEAM1 per plant significantly inhibited the elongation of plant height, and with increasing infestation density, plant height was lower. At $200( \pm 10)$ MEAM1 per plant infestation for $30 \mathrm{~d}$, plant height decreased by $52.67 \%$ compared with the control plants. By contrast, $50( \pm 5)$ and $100( \pm 10)$ T. vaporariorum per plant did not affect plant height of tobacco, $200( \pm 10)$ T. vaporariorum per plant for $30 \mathrm{~d}$ resulted in a slight decrease in plant height, which were $16.62 \%$ lower than those of the control (Figure 1a).

Figure 1. Effects of Bemisia tabaci MEAM1 and Trialeurodes vaporariorum infestation on tobacco height (a), internode length (b), and number of leaves (b).

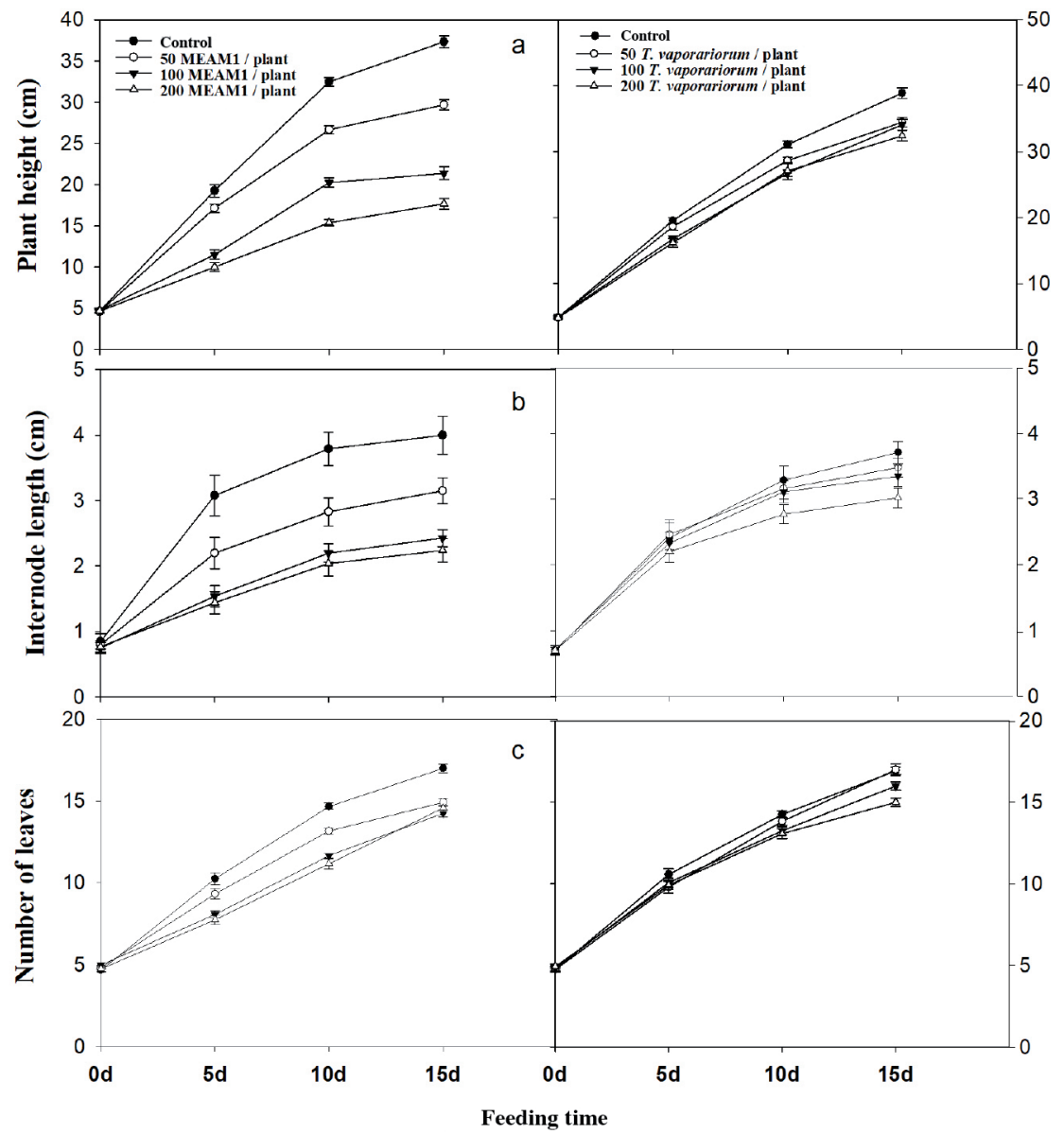

Nicotiana tabacum plants $(\mathrm{n}=12)$ were infested by whiteflies for $0,10,20$, and $30 \mathrm{~d}$ compared to uninfested plants. Same letters indicate nonsignificant difference $(P>0.05)$. 
As low as $50( \pm 5)$ MEAM1 per plant significantly inhibited the elongation of internode length, and with increasing infestation density, internode length was lower. At $200( \pm 10)$ MEAM1 per plant infestation for $30 \mathrm{~d}$, internode length decreased by $44 \%$ compared with the control plants. By contrast, $50( \pm 5)$ and $100( \pm 10) T$. vaporariorum per plant did not affect internode length of tobacco, whereas $200( \pm 10)$ T. vaporariorum per plant for $30 \mathrm{~d}$ resulted in a slight decrease in plant height, which was $18.6 \%$ lower than those of the control (Figure 1b).

MEAM1 and T. vaporariorum feeding tobacco for $30 \mathrm{~d}$ both resulted in a decrease in the number of leaves by about 2 leaves compared with controls, and there is nonsignificant difference between different density treatments (Figure 1c).

MEAM1 infested tobacco exhibited significantly reduced expansion of lower and middle leaves. After $50( \pm 5), 100( \pm$ 10 ), and $200( \pm 10)$ MEAM1 per plant feeding for $30 \mathrm{~d}$, the lower leaf area was reduced by $23.00 \%, 27.49 \%$, and $31.02 \%$, the middle leaf area was reduced by $27.79 \%, 21.40 \%$, and $27.82 \%$ compared to that of the control plant, respectively. On the contrary, MEAM1 infested tobacco plants significantly increased the area of the upper leaves, and there was nonsignificant difference between different densities, which increased by $21.94 \%, 23.21 \%$, and $25.27 \%$, respectively. However, infestation of $50( \pm 5)$ and $100( \pm 10)$ T. vaporariorum per plant did not affect leaf size of tobacco plants, and infestation of $200( \pm 10) T$. vaporariorum per plant for $30 \mathrm{~d}$ only resulted in a slight decrease in lower leaf area, which was $10.61 \%$ lower than that of the control (Table 1 ).

Although MEAM1 infested tobacco resulted in the upper leaf size increasing, upper leaf dry weight $\mathrm{cm}^{-2}$ decreased by $14.9 \%, 23.68 \%$, and $32.64 \%$, at three feeding densities, respectively. Furthermore, $T$. vaporariorum did not cause significant changes in upper leaf dry weight $\mathrm{cm}^{-2}$ (Figure 2).

\section{Effects of MEAM1 and T. vaporariorum infestation on tobacco chlorophyll content}

The chlorophyll content of tobacco upper leaf infested with three densities of MEAM1 was decreased, being 52.63\%, $45.79 \%$, and $49.47 \%$ lower than that of the control, respectively. In contrast, different densities of T. vaporariorum infestation did not lead to a significant decrease in chlorophyll content of tobacco upper leaf (Figure 3).

Table 1. Effects of Bemisia tabaci MEAM1 and Trialeurodes vaporariorum infestation on tobacco leaf area.

\begin{tabular}{|c|c|c|c|c|c|}
\hline Whitefly & Leaf position & $\begin{array}{l}0 \text { Whiteflies per } \\
\text { plant }\end{array}$ & $\begin{array}{l}50 \text { Whiteflies per } \\
\text { plant }\end{array}$ & $\begin{array}{c}100 \text { Whiteflies per } \\
\text { plantt }\end{array}$ & $\begin{array}{l}200 \text { Whiteflies per } \\
\text { plant }\end{array}$ \\
\hline \multirow[t]{3}{*}{ Bemisia tabaci MEAM1 } & Upper leaf & $88.21 \pm 3.05 b$ & $107.56 \pm 3.68 \mathrm{a}$ & $108.68 \pm 6.27 a$ & $110.50 \pm 5.51 \mathrm{a}$ \\
\hline & Middle leaf & $104.08 \pm 5.75 \mathrm{a}$ & $75.10 \pm 4.09 \mathrm{~d}$ & $81.80 \pm 5.03 c$ & $75.13 \pm 3.66 \mathrm{~d}$ \\
\hline & Lower leaf & $92.49 \pm 2.13 \mathrm{a}$ & $71.22 \pm 5.05 b$ & $67.06 \pm 3.06 \mathrm{c}$ & $64.47 \pm 3.79 c$ \\
\hline \multirow[t]{3}{*}{ Trialeurodes vaporariorum } & Upper leaf & $81.05 \pm 3.11 \mathrm{a}$ & $85.75 \pm 2.60 \mathrm{a}$ & $83.17 \pm 2.92 \mathrm{a}$ & $82.58 \pm 4.91 \mathrm{a}$ \\
\hline & Middle leaf & $106.18 \pm 4.75 a$ & $108.76 \pm 6.31 \mathrm{a}$ & $107.93 \pm 4.24 a$ & $105.92 \pm 4.43 \mathrm{a}$ \\
\hline & Lower leaf & $85.74 \pm 3.75 \mathrm{a}$ & $84.14 \pm 4.77 \mathrm{a}$ & $81.15 \pm 3.63 b$ & $81.12 \pm 4.38 b$ \\
\hline
\end{tabular}

Nicotiana tabacum individuals $(\mathrm{n}=12)$ were infested by whitefly for $30 \mathrm{~d}$ compared with un-infested plants. Pairing with the same letter indicates nonsignificant difference $(P>0.05)$.

Figure 2. Effects of Bemisia tabaci MEAM1 and Trialeurodes vaporariorum infestation on tobacco leaf dry weight.

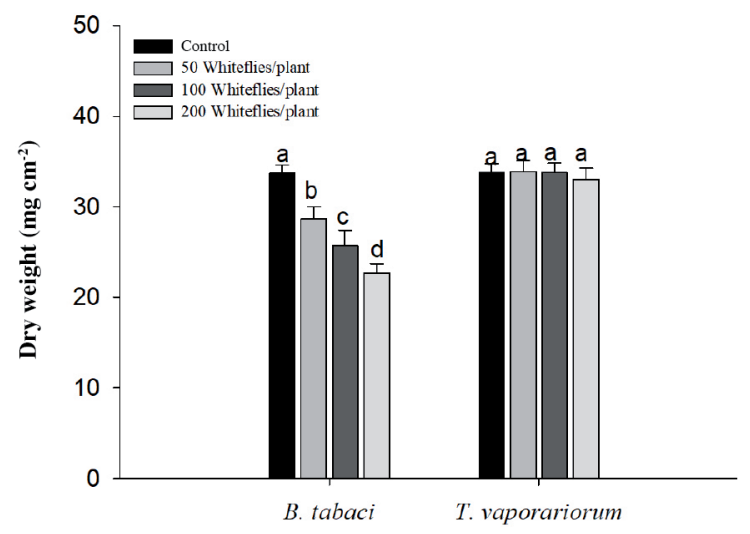

Nicotiana tabacum plants $(\mathrm{n}=12)$ were infested by whitefly for $30 \mathrm{~d}$ compared to uninfested plants. Pairing with the same letter indicates nonsignificant difference $(P>0.05)$. 
Figure 3. Effects of Bemisia tabaci MEAM1 and Trialeurodes vaporariorum infestation on tobacco leaf chlorophyll content.

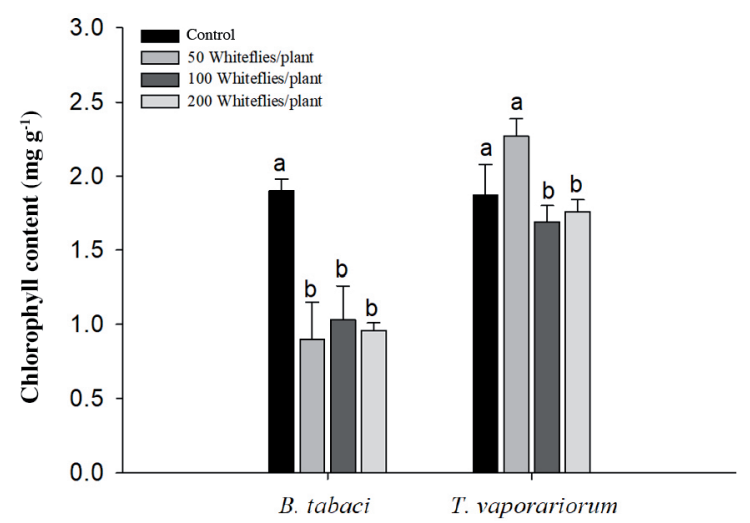

Nicotiana tabacum plants $(\mathrm{n}=4)$ were infested by whitefly for $20 \mathrm{~d}$ compared to uninfested plants. Pairing with the same letter indicates nonsignificant difference $(P>0.05)$.

\section{Effects of MEAM1 and T. vaporariorum infestation on tobacco plant photosynthesis}

The photosynthetic rate of tobacco infested with MEAM1 was significantly decreased and continued to decrease with increasing density, being $64.93 \%, 77.27 \%$, and $88.42 \%$ lower than that of the control, respectively. In contrast, different densities of T. vaporariorum infestation only led to a slight decrease in photosynthetic rate (Figure 4a).

Figure 4. Effects of Bemisia tabaci MEAM1 and Trialeurodes vaporariorum infestation on tobacco leaf photosynthetic rate (a), transpiration rate (b), stomatal conductance (c), and intercellular $\mathrm{CO}_{2}$ concentration (d).
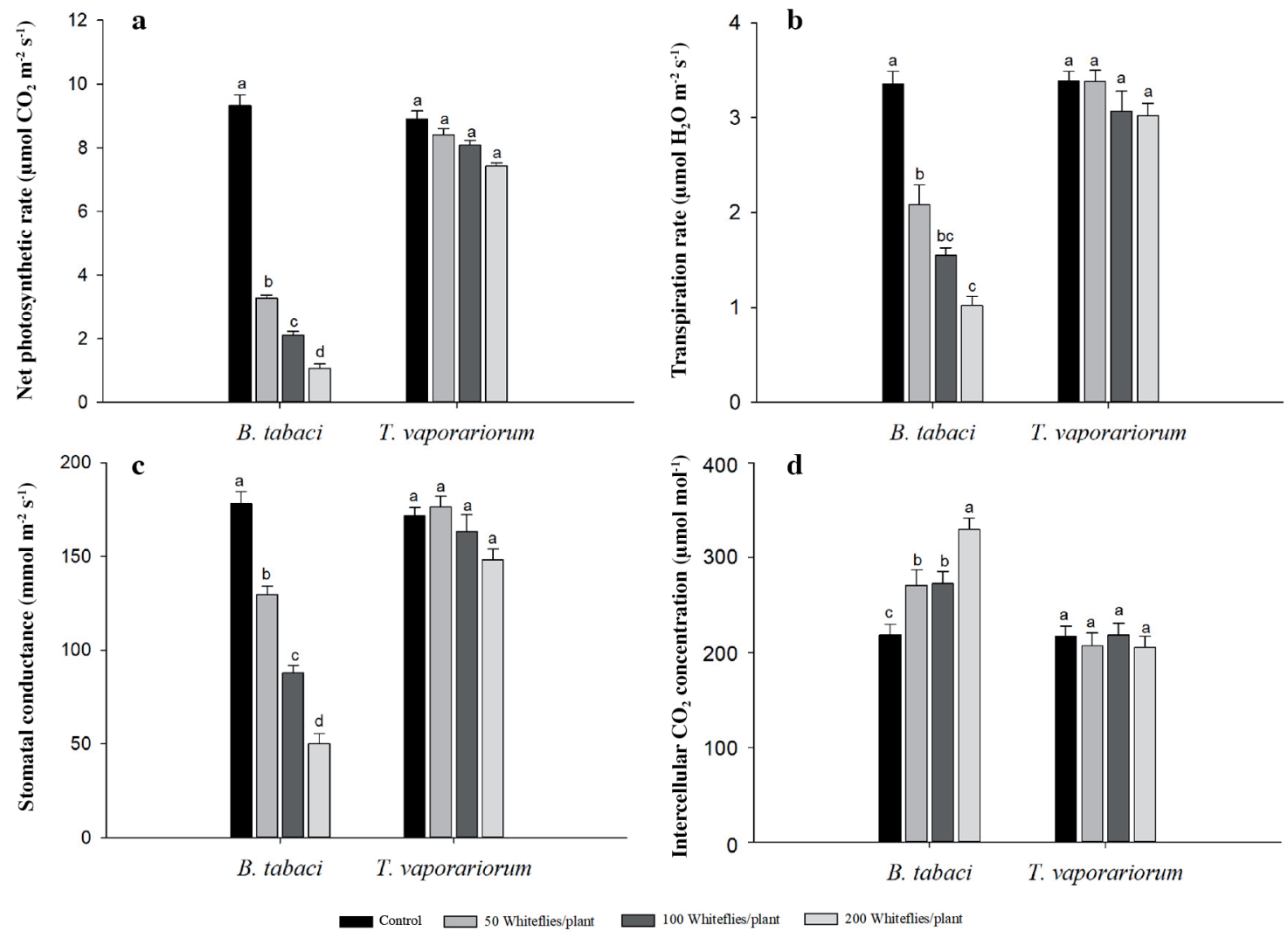

Nicotiana tabacum plants $(\mathrm{n}=12)$ were infested by whitefly for $30 \mathrm{~d}$ compared to uninfested plants. Pairing with the same letter indicates nonsignificant difference $(P>0.05)$. 
The transpiration rate of tobacco infested with MEAM1 decreased significantly and continued to decline with increased feeding density, being $37.91 \%, 53.73 \%$, and $69.55 \%$, respectively. While different densities of T. vaporariorum infestation did not result in a significant reduction in transpiration rate of tobacco plants (Figure $4 b$ ).

The stomatal conductance of tobacco infested with MEAM1 decreased significantly and continued to decline with increased feeding density, being $27.23 \%, 50.68 \%$, and $71.88 \%$, respectively. While different densities of T. vaporariorum infestation did not result in a significant reduction in transpiration rate of tobacco plants (Figure 4c).

The intercellular $\mathrm{CO}_{2}$ concentration of tobacco infested with MEAM1 increased by $23.98 \%, 24.93 \%$, and $51.20 \%$, respectively. While different densities of $T$. vaporariorum infestation did not result in a significant reduction in transpiration rate of tobacco plants (Figure 4d).

\section{Effects of MEAM1 and T. vaporariorum infestation on tobacco hormones contents}

MEAM1 infestation of tobacco plants significantly affected the content of phytohormones (Figure 5). After being MEAM1 infested for $30 \mathrm{~d}$, GA, auxin, and methyl jasmonate (MeJA) contents were reduced by $40.37 \%, 35.24 \%$, and 20.78\%, and CK, ABA, and ETH contents were increased by $46.32 \%, 23.88 \%$ and $36.11 \%$ compared with that of the control, respectively. Unlike MEAM1, T. vaporariorum infestation only caused a slight decline in phytohormones content. After being infested with $T$. vaporariorum for $30 \mathrm{~d}$, the auxin content in tobacco plants was reduced $19.46 \%$, and the MeJA, ABA, and ETH contents were increased by $11.47 \%, 25.45 \%$, and $20.7 \%$, respectively. Significantly, T. vaporariorum infestation did not affect the GA or CK content.

\section{Effects of exogenous GA on MEAM1-infested tobacco plant height}

Exogenous application of GA partially rescued MEAM1 infested inhibition of tobacco plant growth (Figure 6). Although the tobacco plant height of $0.5 \mu \mathrm{M} \mathrm{GA}$ treatment was similar to that of the MEAM1 feeding treatment, the tobacco plant height of 1.0 and $2.0 \mu \mathrm{M} \mathrm{GA}$ treatment was higher than that of the MEAM1 treatment, and increased by $74.33 \%$ and $91.64 \%$, respectively, but remained lower than that of the tobacco plants without MEAM1, being reduced by $22.88 \%$ and $15.22 \%$, respectively.

Figure 5. Effects of Bemisia tabaci MEAM1 and Trialeurodes vaporariorum infestation on tobacco leaf endogenous phytohormones content.

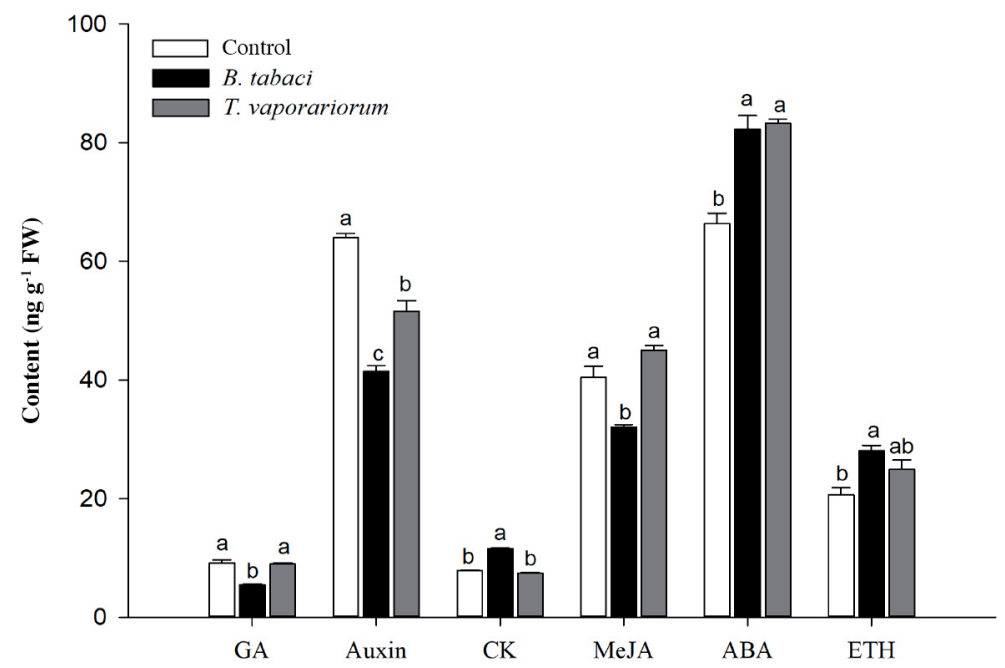

GA: Gibberellin; CK: cytokinin; MeJA: methyl jasmonate; ABA: abscisic acid; ETH: ethylene.

Nicotiana tabacum plants $(\mathrm{n}=4)$ were infested by whitefly for $30 \mathrm{~d}$ compared to uninfested plants. Same letters indicate nonsignificant difference $(P>0.05)$. 
Figure 6. Effects of exogenous gibberellic acid (GA) $(0.5,1.0$ and $2.0 \mu \mathrm{M})$ on tobacco plant height infested with $B$ emisia tabaci MEAM1.

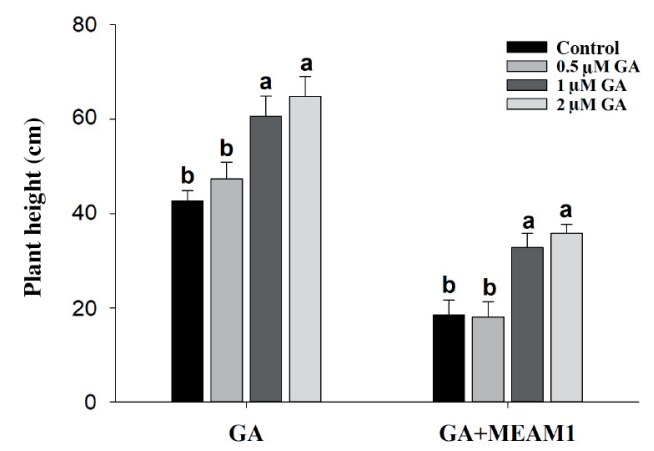

Same letters indicate nonsignificant difference $(P>0.05) .(\mathrm{n}=12)$.

\section{DISCUSSION}

Unlike other phloem-feeding insects, MEAM1 infestation can cause specific morphological characteristics on plant (Zhang et al., 2017a). In this study, compared with T. vaporariorum, MEAM1 infestation inhibited tobacco growth, causing significant reductions in plant height, internode length, and dry weight. In agreement with our results, infestation by Bemisia tabaci reduces Gossypium spp. plant height and number of nodes (Jindal et al., 2009). And high and moderate infestations of Brevicoryne brassicae L. and Lipahis eyrsimi K. on Brassica significantly reduce plant and pod length, pods per plant, grains per pod, and pod weight (Hussain et al., 2015). Importantly, this negative effect mediated by MEAM1 varied with feeding density. As little as the low-density treatment (50 5 MEAM1 per plant) could cause significant inhibition, and this effect was more significant as the density of infection increased. In contrast, T. vaporariorum only caused slight inhibition in the high-density treatment (200 \pm 10 T. vaporariorum per plant). This indicates that the influence of insects on host plants varies with species.

Phloem-feeding insects feed on plant phloem using their stylets, this process may damage the photosynthetic system of the host plant leaves (Bueno et al., 2009). In this research, MEAM1 infestation caused a significant reduction in chlorophyll content, photosynthetic rate, stomatal conductance, and transpiration rate of tobacco upper leaf. However, nonsignificant reduction in tobacco upper leaf was detected after T. vaporariorum infestation. Previous study suggests that MEAM1 nymph feeding on $N$. tabacum L. var. K326 decreased the stability of the oxygen-evolving complex and the electron transport of photosystem II (PSII) (Li et al., 2018). In addition, as stomatal guard cells can sense various biotic and abiotic stress irritation and immediately institute closure under adverse conditions, MEAM1 feeding may reduce leaf photosynthesis in tomato by restricting gas exchange through stomata and reducing chlorophyll content (Marta et al., 2015). In this study, we suspected that chlorophyll content and stomatal closure induced by MEAM1 may be contributing to reduce photosynthetic rate of tobacco leaf.

Plant hormones not only participate in growing process but also transmit environmental signals and activate appropriate responses to biotic and abiotic stresses (De Bruyne et al., 2014). Here, the feeding of MEAM1 resulted in significant changes in the hormone content of tobacco. Among which, auxin, GA, and methyl jasmonate (MeJA) contents were significantly decreased, whereas CK, ABA, and ETH contents were increased. What is different from MEAM1 is that $T$. vaporariorum infestation significantly suppressed auxin synthesis, whereas enhanced contents of MeJA, ABA, and ETH, and no obvious change in GA or CK contents was detected. External application indicated that GA partially alleviated the inhibiting effects on plant height mediated by MEAM1 infestation. Therefore, GA may play a crucial role in the tobacco-specific growth inhibition caused by MEAM1. The chewing herbivore C. suppressalis attack on rice negatively regulates GA biosynthesis, and the attacked plants display dwarfism ( $\mathrm{Li}$ et al., 2015). The response of plants to cold stress is related to GA signaling, accompanied by dwarfism, and the dwarfism can be partially restored by GA application (Zhou et al., 2014; Zhu et al., 2016). Besides, recent research shows that GA signaling can remarkably affect plant photosynthetic capacity via regulating the activity and content of ribulose-1,5-bisphosphate carboxylase, chlorophyll content, and chloroplast biogenesis rates (Jiang et al., 2012). 


\section{CONCLUSIONS}

Compared with Trialeurodes vaporariorum, damage caused by Bemisia tabaci MEAM1 to tobacco plant was more severe and specific. Plant height, internode length, and dry weight were reduced, and there was a significant decrease in chlorophyll content, photosynthetic rate, and stomatal conductance, and the growth inhibition may be related to the reduction of gibberellin content.

\section{ACKNOWLEDGEMENTS}

This work was financially supported by the National Nature Science Foundation of China (30971906 and 317010609).

\section{REFERENCES}

Alonso-Ramirez, A., Rodriguez, D., Reyes, D., Jimenez, J.A., Nicolas, G., Lopez-Climent, M., et al. 2009. Evidence for a role of gibberellins in salicylic acid-modulated early plant responses to abiotic stress in Arabidopsis seeds. Plant Physiology 150:1335-1344. doi:10.1104/pp.109.139352.

Ballina-Gomez, G., Ruiz, S., Chan, C., Latournerie, M., Islas, F., Hernandez, A.I., et al. 2013. Response of Bemisia tabaci Genn. (Hemiptera: Aleyrodidae) biotype B to genotypes of pepper Capsicum annuum (Solanales: Solanaceae). Neotropical Entomology 42:205-210. doi:10.1007/s13744-012-0106-0.

Bueno, A.F., Bueno, R.C.O.F., Nabity, P.D., Higley, L.G., and Fernandes, O.A. 2009. Photosynthetic response of soybean to twospotted spider mite (Acari: Tetranychydae) injury. Brazilian Archives of Biology and Technology 52:825-834. doi:10.1590/S1516-89132009000400005.

Cheng, G.X., Li, R.J., Wang, M., Huang, L.J., Khan, A., Ali, M., et al. 2018. Variation in leaf color and combine effect of pigments on physiology and resistance to whitefly of pepper (Capsicum annuum L.) Scientia Horticulturae 229:215-225. doi:10.1016/j.scienta.2017.11.014.

Costa, E.C.C., Christofoli, M., Costa, G.C.S., Peixoto, M.F., Fernandes, J.B., Forim, M.R., et al. 2017. Essential oil repellent action of plants of the genus Zanthoxylum against Bemisia tabaci biotype B (Homoptera: Aleyrodidae). Scientia Horticulturae 226:327-332. doi:10.1016/j.scienta.2017.08.041

De Bruyne, L., Hofte, M., and De Vleesschauwer, D. 2014. Connecting growth and defense: the emerging roles of brassinosteroids and gibberellins in plant innate immunity. Molecular Plant 7:943-959. doi:10.1093/mp/ssu050.

Hussain, A., Razaq, M., Zaka, S.M., Shahzad, W., and Mahmood, K. 2015. Effect of aphid infestation on photosynthesis, growth and yield of Brassica carinata A. Braun. Pakistan Journal of Zoology 47(5):1335-1340.

Jiang, X., Li, H., Wang, T., Peng, C., Wang, H., Wu, H., et al. 2012. Gibberellin indirectly promotes chloroplast biogenesis as a means to maintain the chloroplast population of expanded cells. Plant Journal 72:768-780. doi:10.1111/j.1365-313x.2012.05118.x.

Jindal, V., Dhaliwal, G.S., Dhawan, A.K., and Dilawari, V.K. 2009. Mechanisms of resistance in cotton to whitefly (Bemisia tabaci): tolerance. Phytoparasitica 37(3):249-254. doi:10.1007/s12600-009-0037-4.

Kim, Y.H., Choi, K.I., Khan, A.L., Waqas, M., and Lee, I.J. 2016. Exogenous application of abscisic acid regulates endogenous gibberellins homeostasis and enhances resistance of oriental melon (Cucumis melo var. L.) against low temperature. Scientia Horticulturae 207:41-47. doi:10.1016/j.scienta.2016.05.009.

Li, Q., Tan, W., Xue, M., and Zhao, H. 2018. Dynamic changes in energy metabolism and electron transport of photosystem II in Nicotiana tabacum infested by nymphs of Bemisia tabaci (Middle East-Asia Minor 1). Arthropod-Plant Interactions 12:505-515. doi:10.1007/s11829-018-9594-0.

Li, Q., Tan, W., Xue, M., Zhao, H., and Wang, C. 2013. Dynamic changes in photosynthesis and chlorophyll fluorescence in Nicotiana tabacum infested by Bemisia tabaci (Middle East-Asia Minor 1) nymphs. Arthropod-Plant Interactions 7:431443. doi:10.1007/s11829-013-9260-5.

Li, J.R., Yu, K., Wei, J.R., Ma, Q., Wang, B.Q., and Yu, D. 2010. Gibberellin retards chlorophyll degradation during senescence of Paris polyphylla. Biologia Plantarum 54:395-399. doi:10.1007/s10535-010-0072-5.

Li, R., Zhang, J., Li, J.C., Zhou, G.X., Wang, Q., Bian, W.B., et al. 2015. Prioritizing plant defence over growth through WRKY regulation facilitates infestation by non-target herbivores. eLife 4:e04805. doi:10.7554/eLife.04805.

Marta, D.T.Z., Littlejohn, G., Jayaraman, S., Studholme, D., Bailey, T., Lawson, T., et al. 2015. Chloroplasts play a central role in plant defence and are targeted by pathogen effectors. Nature Plants 1(6):15074. doi:10.1038/nplants.2015.74.

Masuda, K., Kat, M., and Saito, T. 2016. Reduction in carotenoid and chlorophyll content induced by the sweet potato whitefly, Bemisia tabaci. Scientia Horticulturae 200:102-104. doi:10.1016/j.scienta.2016.01.010.

Pandey, N., Bharti, K., Karnatak, A., and Singh, C. 2013. Effect of aphid herbivory on physiological characters of rapeseedmustard genotypes. Journal of Life Sciences 10:930-932. 
Pusittigul, I., Kondo, S., and Siriphanich, J. 2012. Internal browning of pineapple (Ananas comosus L.) fruit and endogenous concentrations of abscisic acid and gibberellins during low temperature storage. Scientia Horticulturae 146:45-51. doi:10.1016/j.scienta.2012.08.008.

Schaeffer, R.N., Wang, Z., Thornber, C.S., Preisser, E.L., and Orians, C.M. 2018. Two invasive herbivores on a shared host: patterns and consequences of phytohormone induction. Oecologia 186:1-10. doi:10.1007/s00442-018-4063-0.

Stephens, A.E., and Westoby, M. 2015. Effects of insect attack to stems on plant survival, growth, reproduction and photosynthesis. Oikos 124:266-273. doi:10.1111/oik.01809.

Su, F., Villaume, S., Rabenoelina, F., Crouzet, J., Clement, C., Vaillant-Gaveau, N., et al. 2017. Different Arabidopsis thaliana photosynthetic and defense responses to hemibiotrophic pathogen induced by local or distal inoculation of Burkholderia phytofirmans. Photosynthesis Research 134:201-214. doi:10.1007/s11120-017-0435-2.

Wolters, H., and Jurgens, G. 2009. Survival of the flexible: hormonal growth control and adaptation in plant development. Nature Reviews Genetics 10:305-317. doi:10.1038/nrg2558.

Xue, M., Wang, C.X., Bi, M.J., Li, Q.L., and Liu, T.X. 2010. Induced defense by Bemisia tabaci biotype B (Hemiptera: Aleyrodidae) in tobacco against Myzus persicae (Hemiptera: Aphididae). Environmental Entomology 39:883-891. doi:10.1603/EN09307.

Zhang, P.J., Li, W.D., Huang, F., Zhang, J.M., Xu, F.C., and Lu, Y.B. 2013. Feeding by whiteflies suppresses downstream jasmonic acid signaling by eliciting salicylic acid signaling. Journal of Chemical Ecology 39:612619. doi:10.1007/s10886-013-0283-2.

Zhang, X., Sun, X., Zhao, H., Xue, M., and Wang, D. 2017b. Phenolic compounds induced by Bemisia tabaci and Trialeurodes vaporariorum in Nicotiana tabacum L. and their relationship with the salicylic acid signaling pathway. Arthropod-Plant Interactions 11:659-667. doi:10.1007/s11829-017-9508-6.

Zhang, J., Wang, L., Zheng, Y., Feng, J., Ruan, Y., Diao, S., et al. 2017a. Effects of Bemisia tabaci (Gennadius) infestation and squash silverleaf disorder on Cucurbita pepo L. leaf. Scientia Horticulturae 217:8-16. doi:10.1016/j.scienta.2017.01 .017.

Zhang, X., Xue, M., and Zhao, H. 2015. Species-specific effects on salicylic acid content and subsequent Myzus persicae (Sulzer) performance by three phloem-sucking insects infesting Nicotiana tabacum L. Arthropod-Plant Interactions 9:383391. doi:10.1007/s11829-015-9385-9.

Zhou, M., Xu, M., Wu, L., Shen, C., Ma, H., and Lin, J. 2014. CbCBF from Capsella bursa-pastoris enhances cold tolerance and restrains growth in Nicotiana tabacum by antagonizing with gibberellin and affecting cell cycle signaling. Plant Molecular Biology 3:259-275. doi:10.1007/s11103-014-0181-1.

Zhu, Z., Ding, Y., Zhao, J., Nie, Y., Zhang, Y., Sheng, J., et al. 2016. Effects of postharvest gibberellic acid treatment on chilling tolerance in cold-stored tomato (Solanum lycopersicum L.) Fruit Food and Bioprocess Technology 9:1202-1209. doi:10.1007/s11947-016-1712-3. 